Paul Schostakowsky.

\title{
EUROPA Y RUSIA (1)
}

\section{E1 «Occidentalismo»y el «Rusismo», las dos co- rrientes principales de la cultura rusa}

遛亡

progreso cultural de los antiguos rusos, cuyo espíritu altamente humanitario distinguía el $\mathrm{Kiev}$ de los siglos $\mathrm{X}$-XII, se encontró groseramente atropellado durante el nuevo período de la historia rusa, que empezó con el siglo XIII. La masa de la población del gran ducado de Kiev, huyendo de los enemigos de la estepa, se concentró, según lo hemos visto, entre el río Oka y el curso superior del Volga, en la región en que existían ya ciudades fundadas en los tiempos inmemoriales, como Vladimir-del-Kliazma, Suzdal, Rostov, ciudades que ahora empezaron a rivalizar para recoger la herencia de Kiev, es decir, para hacerse capitales del gran ducado ruso.

Desde el siglo XIII y hasta la mitad del siglo XV, mientras duraba la dispersión del pueblo ruso y el centro nacional vagaba de una ciudad a otra, la población, alejada de sus antiguos mercados de comercio exterior, tuvo que abandonar las industrias silvestres, que le proporcionaban los objetos de su exportación, y buscar en la agricultura los medios de subsistencia. Este cambio de actividades dí́ en seguida otro aspecto a Rusia. La población, en vez de concentrarse en las ciudades y ocuparse del comercio, se dispersó en el campo; la Rusia comercial, urbana, se volvió campestre, agrícola, es decir, se puso en condi-

(1) Véase el número 67 de Atenea en que se publicó la primera parte de este trabajo. 
ciones mucho más desfavorables para el desarrollo cultural. Además, con la dispersión de las poblaciones urbanas y con la supresión del comercio exterior, desapareció el capital y la riqueza y la vida se hizo mucho más pobre que antes.

Al mismo tiempo la división del patrimonio paterno entre los descendientes de los grandes duques de Kiev llegó a su colmo. Existían ducados que se componían de una sola aldea. Este empobrecimiento general fué otra desventaja cultural: desaparecieron los mecenas y bajó el nivel de la clase dirigente. A todo esto hay que añadir un nuevo factor desfavorable para la cultura rusa: la escasez de las relaciones con los pueblos cultos $y$, en cambio, el contacto permanente con los tártaros, que se hallaban en un grado de cultura muy inferior al de los rusos.

Claro que no era esta la época en que el pensamiento ruso hubiera podido elevarse como en Kiev a la concepción del paneslavismo o lucír las tendencias humanitarias de sus antiguos duques, pero, como siempre sucede en la historia paradojal de Rusia, fueron precisamente esos males los que permitieron realizar un gran bien.

En realidad, el yugo tártaro despertó la idea de la unión nacional entre la masa del pueblo, reunió a este alrededor de su iglesia y di6 al Metropolitano de toda la Rusia (dignidad superior de la Iglesia rusa de entonces) la autoridad de la cual carecían los príncipes: la de la unión nacional del pueblo entero alrededor de la cátedra metropolitana. Y el día en que Moscú tuvo por fin un príncipe bastante inteligente y enérgico para empezar la tarea de la reunión de la tierra rusa, este fué sostenido por la Iglesia, que agrupó los espíritus y las voluntades dispersas alrededor del mismo ideal patriótico, cuyo alcance, los demás príncipes, empobrecidos y desunidos, no tenían ya medios de impedir.

Pero antes de seguir el hilo de mi relato me parece interesante aclarar una duda que puede nacer en la mente de muchos lectores. Apenas los rusos fueron dejados a sí mismos, apenas se hallaron aislados del Occidente, la cultura, que hacía pasos tan rápidos en la Rusia de Kiev, empezó a retroceder.

Cierto, no cabe duda de que el aislamiento es el peor enemigo de la cultura en general, pero sería un error grave achacar toda la culpa de la detención que la cultura rusa sufrió durante aquella época únicamente a su soledad. La cultura en general es el más frágil de todos los fenómenos sociales y para cultivarla se necesitan, como para una flor delicada, condiciones especialmente favorables de la vida y del ambiente que hubiera podido ser su fomento y su guarda. La cultura tiene ade- 
más de particular, que mientras sus alcances materiales crean la igualdad, en la forma de una nivelación general de los modales de la vida material - y para entenderlo basta darse cuenta del papel democratizante de los transportes en común, de las distribuciones de agua, gas y electricidad-, sus alcances espirituales (dejando aparte los grandes y sonoros principios), crean la desigualdad, ya que las masas del pueblo, aun por la ley mecánica de inercia, no pueden seguir el movimiento de su propia clase intelectual y dirigente; y si el poder de ésta se derrumba y las masas suben en su lugar, sucede lo que sucedió en Rusia con el advenimiento del bolchevismo: miseria, miseria material y espiritual a la vez.

Entre todos los tesoros espirituales no hay más que uno que está al alcance de todos, de los ricos y de los pobres, de los cultos y de los incultos: la religión, y la causa de su accesibilidad universal es la fe, que no depende de la razón, sino del corazón (verdad que ignoran los que discuten la existencia de Dios). Lo que sucedió con el pueblo ruso durante el período que nos interesa fué, precisamente, por un lado, la decadencia de su clase dirigente, decadencia provocada por la ruina y el empobrecimiento general del estado-lo que creó condiciones desfavorables para el cultivo de la cultura - y, por otro lado, el crecimiento de la autoridad moral de la Iglesia, que resultó ser la gran unificadora del pueblo, oprimido por los tártaros.

La nivelación del pueblo entero se hizo con tanta más facilidad cuanto que la diferencia cultural entre la clase dirigente y la masa del pueblo no podía ser entonces tan profunda como volvió a serlo después de la reforma de Pedro el Grande, y el foso que separaba a los dirigentes de sus administraciones fué llenado fácilmente. Pero si aquella nivelación se realizó con gran detrimento para la cultura, en cambio el espíritu de la unión nacional se ha beneficiado grandemente de las nuevas condiciones de vida, manifestándose, ante todo, en la defensa de la religión ortodoxa, la que supo defender realmente, conservándola en toda su integridad.

Hay que fijarse en este período de la historia rusa durante el cual empezó la estupenda fusión de todas las clases de la sociedad rusa, fusión rota solamente al fin del siglo XVII, en vísperas de las reformas de Pedro el Grande, por la disidencia de los «viejos creyentes», y que tuvo su expresión más viva en el reino moscovita, donde el pueblo entero, empezando por el zar, vivía la misma vida religiosa y familiar, tenía los mismos gustos y, por tanto, rezaba y razonaba del mismo modo. Creo aún que si el pueblo de entonces no hubiera vivido como 
un solo bloque unido, nunca la nación rusa hubiera podido hacer lo que hizo, realizando su estupenda expansión territorial.

El centro de aquel desarrollo fenomenal, Moscú, se convirtió en la capital del modesto ducado moscovita solamente en 1263, pero su crecimiento fué rápido, debido a su situación geográfica en el cruce de los tres caminos principales de la Rusia de entonces, así como de la ruta navegable que unía el curso superior del Volga al curso mediano del Oka. De todas partes los rusos, amenazados por los enemigos exteriores, se dirigían a Moscú. La posición de la ciudad en el centro de la Rusia de entonces favorecía al joven ducado políticamente, ya que todos los golpes exteriores caían sobre los ducados que la rodeaban.

En 1326 fué transferida a Moscú la cátedra del Metropolitano. Desde este momento la Iglesia empieza a sostener con toda su autoridad las actividades de los herederos del primer duque moscovita Daniel, actividades dirigidas a través de varias generaciones, con una constancia y perseverancia feroz, hacia el mismo fin de la unión de la tierra rusa.

En 1380, uno de aquellos príncipes, Dmitri Donskoy (Demetrio del Don), infligió a la horda tártara, encabezada por Mamai, la primera derrota en Kulikovo Pole. Desde entonces la lucha con la horda y los reinados tártaros que derivaron de ésta, fué a la vez militar y cultural. Rusia, siendo un estado más culto, gobernado por un poder mejor organizado, atraía los mejores elementos tártaros, que abandonaban sus estepas y venían a vivir en las ciudades rusas. Muchos de ellos se convertían al cristianismo y llegaban a tener situaciones muy elevadas en la jerarquía administrativa rusa. Hasta el zar Boris Godunov (1598-1605) descendía de un príncipe tártaro emigrado a Rusia. Desde luego, después de la primera victoria sobre la horda pas6 exactamente un siglo antes de que Iván III derrumbara definitivamente, en 1480, el yugo humillante; en cuanto a la pacificación y la asimilación de los tártaros, que continuaban rodeando Rusia del lado sud-sudeste-este, se necesitaron tres siglos más. Fué Catalina la Grande, la que en 1783 llevó a cabo la última operación contra los tártaros de Crimea, y pudo anexar a su Imperio el último baluarte agareno.

Y ahora rehacemos el cálculo: dos siglos de lucha con los nómades, «pechenegos». y "polovtzi», predecesores de los tártaros en las estepas del sud de Rusia; un siglo y medio de yugo tártaro efectivo, absoluto, es decir, cuando Rusia no era más que un feudo de la horda; un siglo de lucha para derribar aquel yugo, y luego tres siglos de esfuerzos para liquidar los reinos 
tártaros, derivados de la horda, con la conclusión definitiva de aquel estado de guerra permanente en 1783, es decir, solamente seis años antes de la gran revolución francesa. Total, siete siglos y medio sobre los diez siglos y medio de existencia de Rusia. iY hay gente que quiere ver europeos en los rusos!

La asimilación de los tártaros por la Rusia moscovita era, desde el principio del yugo, un fenómeno continuo y extenso. No se trataba solamente de la adopción de individuos: los tártaros llegaban por familias y partidas, a veces de centenares y millares. Así, bajo Vasili el Ciego (1425-1462), el príncipe Kazim de Kazán vino a arraigarse en Rusia con toda una tribu; las tierras que les fueron asignadas ocupaban un círculo de doscientos kilómetros alrededor de la ciudad Gorodetz Mescherski, que desde aquel tiempo tom6 el nombre de Kazimov. Bajo Iván el Terrible (1533-1584) muchos «murzás» (nobles) tártaros vinieron a fijarse en los alrededores de la ciudad Romanov en Volga. En las antiguas listas provinciales de Moscú los nombres tártaros se hallan por centenares. Ya bajo Iván III (14621505) el "Libro de la nobleza de viejo linaje», revelaba un $17 \%$ de nombres tártaros.

Prácticamente el reino moscovita estaba ya formado por la mitad del siglo XV; en qué grado se encontraba entonces la cultura rusa, es fácil de imaginar, meditando sobre el siguiente cálculo: durante los primeros 234 años (1228-1462) de existencia de la Rusia nordeste, esta soportó, según el historiógrafo Kliuchevski, 90 luchas internas y 160 guerras exteriores. En medio de semejantes condiciones de vida, Iván I ha sabido dotar a su país de un código que reglamentaba las condiciones de la propiedad campestre, las normas de policía y de justicia criminal, y que fué copiado, a la manera de La Verdad Rusa, sobre los documentos bizantinos del siglo VIII. En aquella época la influencia bizantina continuaba haciéndose sentir en Rusia, tomando en cierta medida un aspecto "nacional ruso», lo que era natural, ya que las necesidades de la Iglesia, que dependía de los patriarcas orientales, obligaban a los rusos a mantener relaciones continuas con Constantinopla, a pesar de cualesquiera dificultades del orden material, aceptando lo que venía de allí con cariño de correligionarios para los cuales el espíritu de fraternidad facilitaba la asimilación de lo ajeno, dándole en seguida el color de lo suyo, propio, familiar.

Aquella influencia se hizo sentir poderosamente con la ocasión del segundo matrimonio de Iván III, que enviudó en 1467. En aquellos tiempos vivía en Roma, Sofía Paleólogo, sobrina del último emperador de Bizancio, que los turcos tomaron en 
1453. Iván III la hizo venir a Moscú y se casó con ella en 1472. Las crónicas pintan a Sofía como a una mujer extraordinariamente gorda y astuta. Su influencia sobre Iván III se ejercitaba principalmente en el dominio de la creación de una severa etiqueta, que la corte de Moscú hasta entonces desconocía por completo. Las crónicas dicen que los boyardos de Iván III, antes de la llegada de Sofía, llegaban hasta insultar a su duque en el calor de las discusiones. La llegada de la princesa de Zargrad (Ciudad del Zar), como llamaban los rusos a Constantinopla, ha coincidido con la fusión, en gran parte acabada, de la Gran Rusia, lo que originaba ya la idea del estado nacional ruso, y esto sin precisar sus límites, es decir, dejando que los fijasen los éxitos de las armas y los progresos de la colonización rusa. Con esto la situación del ducado de Moscú cambió por completo. Antes sus duques guerreaban con sus propios paisanos y con los tártaros, mientras que ahora, habiendo absorbido los principales ducados que las rodeaban, los moscovitas se hallaban frente a Polonia, Suecia y Alemania, representada en las provincias bálticas por las órdenes guerreras Teutónica y Livonesa. Renacía la idea nacional de la Rusia de Kiev de los siglos XI-XII, así como el sueño del paneslavismo.

Al desarrollo de aquellas pretensiones nacionalistas el casamiento de Iván III con Sofía Paleólogo contribuyó poderosamente, ya que permitió fomentar la idea de que el duque de Moscú no sólo era el soberano nacional de toda la tierra rusa, sino el heredero político del Imperio de Oriente, y como tal el único defensor de la religión ortodoxa. De aquí el título de zar, que no es otro que el césar romano en la transcripción eslava: z'sar.

Desde luego en el sentido puramente cultural hasta aquella recrudescencia de la influencia bizantina fué bastante limitada. La corte rusa hizo venir de Italia algunos arquitectos y artesanos: Iván III construyó una nueva catedral, la Uspenski, un nuevo palacio, la famosa Granovitaia Palata, maravilla que existe todavía; cambió los modales de la vida palatina. Puede ser que estos cambios se reflejaran sobre la vida de los boyardos que rodeaban el trono; pero fuera de la Iglesia y de la vida familiar, es difícil hallar huellas de la influencia bizantina en la vida cultural de la nación rusa. Aun en la Iglesia aquella influencia era muy relativa, a pesar de su dependencia canónica de los patriarcas orientales. En primer lugar la Iglesia rusa se hizo rápidamente, según hemos visto, Iglesia nacional, y en segundo lugar, los griegos, desde el concilio de Florencia de 1434, parecían sospechosos a los rusos desde el punto de 
vista de su integridad religiosa, por haber aceptado la forma de la unión de las dos Iglesias, propuesta por dicho concilio. Consecuentemente el pueblo moscovita se sentía ahora como el único baluarte terrestre de la verdadera fe ortodoxa.

En cuanto a la influencia occidental, de esta no es todavía el caso de hablar. Entre Rusia y el Occidente existían solamente relaciones comerciales, que además sostenía s6lo Novgorod con sus lugares dependientes, por tener una vía navegable directa, que conducía por el Voljov, el lago de Ladoga y Neva al Báltico. De este modo Moscú, aislada hasta la mitad del siglo XV de las influencias occidentales, se entregaba al fomento de sus tradiciones religiosas y al desarrollo de su suficiencia nacionalista, que llegó hasta considerarse como heredera de Bizancio y una tercera Roma. Ambas tendencias, la religiosa y la nacionalista, se fundían en un sola, por tener la misma fuente: la Iglesia. Esta era el símbolo de la unión nacional en medio de los enemigos políticos y religiosos, que rodeaban el país. La celebración de los oficios divinos en el idioma ruso facilitó enormemente aquella fusión del pueblo con su Iglesia nacional. Para entenderlo hay que establecer un paralelo: los católicos en cualquier parte del mundo oyen durante la misa las mismas palabras latinas del sacerdote: Dóminus vobiscum!, y si ignoran el latín no las entienden, mientras que los rusos entienden cada palabra y consideran su Iglesia como una Iglesia propia nacional, no sólo porque ella les habla en su idioma, sino también porque esto no se repite en ningún otro país: la Iglesia ortodoxa oficia en Grecia en griego, en Serbia en serbio y en Rumania en rumano, etc. Claro está que en estas condiciones los rusos, rodeados por los paganos y mahometanos del lado sudeste y por los católicos y luego protestantes al noroeste, se unían alrededor de su Iglesia como si esta fuera una bandera nacional. Son condiciones en que el papel político de la religión puede ser tremendo.

¿Cómo había aprovechado la Iglesia su enorme autoridad desde el punto de vista puramente cultural? Las preocupaciones de la instrucción pública la dejaban completamente fría. La Iglesia ortodoxa rusa se limitaba a cuidar las almas y vigilar por la salvación de éstas, sin interesarse en absoluto por el desarrollo individual de los fieles. A pesar de esto, aun en el camino estrechamente religioso, del cual sus actividades no se desviaban nunca, estas sirvieron como no se puede mejor los intereses estadistas y civilizadores del "zarstvo" moscovita. Hablo del papel colonizador de los monasterios de entonces. El estado moscovita se desarrollaba alrededor de Moscú, en 
una region bastante estrecha, comprendida entre el curso superior del Volga y el Oka, pero quedaban extensiones del territorio supuesto nacional, prácticamente ilimitadas, al norte $\mathrm{y}$ al oriente del Volga. Precisamente en estas dos direcciones se desarrollaba la emigración de los ascetas, que buscaban en la soledad de los bosques vírgenes condiciones favorables para sus prácticas religiosas. Pero apenas un monje se establecía en un lugar apartado, otros religiosos se juntaban a él; se formaba un pequeño monasterio, se erigía una iglesia, y tras los monjes venían los campesinos, que buscaban tierras vírgenes o condiciones de vida mejores en regiones todavía no registradas por el fisco moscovita. Así, perseguidos por el «mundo pecador», los santos padres adelantaban siempre más a lo profundo del bosque, hasta que en la dirección norte los detuvo el mar Blanco. Entonces los santos Savati y Zócima se refugiaron er. las islas Solovetzki, pero fueron alcanzados por sus adeptos y discípulos, que en 1429 principiaron allí la construcción del célebre monasterio, que los bolcheviques transformaron, cinco siglos después, en una prisión política.

La Iglesia ortodoxa, como toda Iglesia, era conservadora, y su clero, que formaba la capa principal de la gente letrada rusa, se oponía con porfía a la influencia "occidentalista", por miedo del veneno que las ciencias de los «latinistas» ocultaban para las almas rusas y la integridad de la religión ortodoxa. Pero hubiera sido un error pensar que el clero o, por su insinuación, el estado, tomaba cualesquiera medidas preventivas o represivas para impedir la introducción de ciencias occidentales; ya he dicho que, empezando por el zar, la nación moscovita razonaba toda del mismo modo, todos temían en la misma medida la importancia espiritual del Occidente, todos celebraban el siglo dorado del «rusismo».

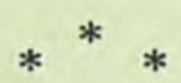

Desde luego cuando la Rusia moscovita, a mediados del siglo XV, formó su núcleo nacional, y ante sus príncipes se levantaron problemas completamente nuevos que los ponían cara a cara con sus vecinos occidentales-los polacos, lituanos, alemanes y suecos-, la deficiencia de los métodos y de -los medios, es decir, la deficiencia cultural de los moscovitas frente a sus enemigos occidentales se hizo sentir en seguida. Desde luego la presunción nacional era tan grande que nadie quiso buscar los remedios en el Occidente. Aun reconociendo sus faltas y defectos, los rusos, sicmpre desconfiados de las ciencias 
-latinistas», se esforzaban en encontrar esos remedios en su casa. Desde luego, la Reforma, que Lutero empeź́ en Europa en 1517, tuvo cierta repercusión en Rusia, en el sentido del ablandamiento de la profunda antipatía y desconfianza con que los rusos miraban al Occidente. Los protestantes les inspiraban menor aprensión que los católicos por no pretender el predominio religioso, y luego porque las objeciones que los protestantes oponían a Roma concordaban en varios puntos con las enseñanzas ortodoxas.

En 1533, Iván el Terrible firmó con los ingleses un tratado de comercio, que abría a los negociantes de Inglaterra la vía de Arcángel. Desde luego nada cambió radicalmente en lo que se refiere a la corriente cultural del Occidente, hasta el principio del siglo XVII. Lo que trajo un cambio fundamental en la mentalidad del pueblo ruso entero, lo que abrió a la influencia "occidentalista" la puerta de la antigua Moscovia, fué el período de «interregno»- «el tiempo turbio», como lo llaman los historiógrafos rusos. Este duró catorce años desde la muerte en 1598 del zar Feodor, último zar de la primera dinastía moscovita, y hasta la elección de la nueva dinastía de Romanov, en 1613.

Durante aquel período el estado moscovita se desagregó por completo: los polacos se apoderaron de Moscú, el pueblo ruso vió el derrumbe de todas sus tradiciones políticas y finalmente tuvo que tomar parte activa en la salvación de su patria no sólo como defensor de su tierra natal, sino como legislador y organizador del estado, eligiendo al nuevo zar y restableciendo la autoridad del poder supremo. En una palabra, fué la misma vida la que arrebato al pueblo con una violencia extrema de su letargia política y mental y le puso en la obligación de resolver los problemas orgánicos que están en la base de todo estado. Por primera vez al lado del poder supremo del zar apareció la voluntad del pueblo, fuerza política completamente olvidada en la Rusia de entonces. Desde luego el apego a las formas políticas tradicionales era tan grande que, a pesar de la lucha social que sacudió el país, al mismo tiempo éste encontró la solución de todos su's males en el restablecimiento de la monarquía absoluta.

Pero desde el principio del siglo XVII se trataba de luchar con los vecinos occidentales que aprovecharon el período de «interregno" para quitar a los rusos sus posiciones adelantadas en la frontera occidental, y esta lucha puso en evidencia el atraso, el estado de inferioridad en que los rusos se hallaban frente a enemigos más cultos, mejor armados y organizados. 
Los más obstinados de los moscovitas tuvieron que reconocer que esta vez los remedios caseros eran insuficientes e ineficaces, que para nada les servían las tradiciones y costumbres de la antigüedad, que para asegurar la existencia de su patria había que tomar prestados a los occidentales los medios y métodos para vencerlos...

Puede ser, y aun es cierto que entre los rusos existieran hombres que apreciaban la ciencia occidental, tal cual, es decir, por su valor intrínseco, pero la masa del pueblo y el estado tomaron la cultura europea desde el punto de vista estrechamente utilitario, es decir, como un arma, y más tarde, Pedro el Grande lo expresó con mucha claridad cuando en el campo de Poltava, el día en que fué destruída la potencia militar de Suecia, festejando la victoria rusa, brindó por la salud de los generales suecos, sus huéspedes prisioneros, diciendo: «iPor nuestros maestros!» Este punto de vista, que apreciaba la cultura europea como un medio, y en la medida de su valor utili tario, hay que retenerlo, ya que desde el principio del siglo XVII y hasta la mitad del siglo XIX, este fué el punto de vista del gobierno y de las clases dirigentes rusas en su mayoría, punto de vista que explica muchos enigmas del pasado, del mismo modo que el «absolutismo ilustrado» de los zares letrero elegante, bajo el cual se ocultaban los abusos del poder absoluto.

De acuerdo con aquel fin utilitario, el gobierno moscovita empez6́ con hacer llegar del extranjero, principalmente de Alemania, a los militares profesionales por centenares. La creación del ejército regular adelantaba con tanta rapidez, que bajo el segundo Romanov los rusos podían ya oponer a los polacos y suecos veinticinco regimientos regulares de caballería y treinta y ocho de infantería, desde luego todos, salvo tres, mandados por jefes extranjeros.

Claro que los medios financieros del estado, apenas salido de un período de guerras civiles y exteriores que lo devastaron por completo, no podían satisfacer las nuevas exigencias del fisco; entonces, bajo el zar Alejo (1645-1676), el gobierno moscovita tomó las medidas que hoy día usan los bolcheviques: el fisco compraba a los comerciantes y productores rusos, en forma obligatoria y al precio que fijaba el mismo gobierno, las mercancías que tenían mayor demanda en el extranjero: lino, cáñamo, pieles, etc.; las pagaba en moneda de cobre y las vendía a los negociantes europeos, cobrando en moneda de plata. Exactamente lo mismo hacen ahora los bolcheviques, no sólo como monopolistas del comercio de exportación, sino comprando a 
precios obligatorios y con rublos soviéticos desvalorizados, mientras que sus compradores occidentales les pagan con d6lares, libras esterlinas, francos y marcos.

Desde luego la organización del ejército regular, bien que con carácter temporal, exigía, además de los cuadros, la creación de varias industrias, que hubieran podido alimentar y proveer al ejército de todo lo que necesitaba; y esto a su vez obligaba al gobierno a empezar la explotación de las riquezas minerales. Bien que en la Rusia moscovita ya se extraía el hierro, cerca de Ustiuyna y Tula, y en esta última ciudad existían establecimientos que fabricaban armas y aun escopetas, ahora, para dar mayor desarrollo a aquellas industrias, el gobierno busc6 en el Occidente a los técnicos y a los capitales. De esta manera nacieron en Rusia importantísimas industrias metalúrgicas, que a mediados del siglo XVII ya permitían a los rusos empezar la fabricación de todos los objetos de armamento en su casa, Después de los metalúrgicos Moscú contrató al extranjero artesanos de las profesiones más variadas, con la obligación de hacer enseñar sus oficios "a nuestra gente, sin ocultarle secreto alguno».

Ya en el siglo XVI, bajo Iván el Terrible, en Moscú se formó el «barrio alemán», donde vivían los pocos extranjeros, médicos, boticarios y artesanos, empleados del gobierno moscovita, pero, las tormentas del «interregno» los dispersaron. Desde luego a mediados del siglo XVII la cantidad de los "alemanes» - militares, técnicos, médicos, artesanos, industriales, comerciantes, etc.-que vivían en Moscú, era tan grande y tan graves parecían los inconvenientes de su contacto directo con la población que, en 1652, todos los extranjeros fueron "concentrados nuevamente en un barrio especial, en que les fueron donadas casas y huertos, de acuerdo con la situación de cada uno. De esta manera se formó en la periferia oriental de Moscú toda una ciudad "alemana", de cuya importancia puede dar una idea la existencia en su recinto de cuatro iglesias, tres luteranas y una reformada, así como de una escuela alemana.

Siempre persiguiendo la idea utilitaria, lo primero que las clases dirigentes tomaron prestado a los extranjeros, cuya vida podían observar, fueron las comodidades materiales de la vida europea, y luego las distracciones. La música y los teatros interesaban a tal punto a la corte de Moscú, que a las embajadas, que ahora se mandaban a menudo a los países europeos, les fué ordenado presentar descripciones detalladas de los espectáculos que estas presenciaban en las cortes europeas.

Esta fué la manera en que la influencia «occidental» penetró 
en Rusia, con ciertos derechos de ciudadanía, encontrando ya instalada en el país la influencia bizantina, que en aquellos tiempos, bajo el disfraz nacional ruso, parecía ya "rusismo». La diferencia entre ambas influencias era grande en aquellos tiempos: la manera cómo los rusos tomaron la corriente "occidentalista», es decir, sólo por su lado utilitario, indicaba a esta el dominio puramente material, mientras que la influencia bizantina perter necía enteramente al dominio espiritual, limitándose a dirigir la vida religiosa y moral, sin intervenir en absoluto en los demás aspectos de la vida nacional. Desde luego, limitando su acción al dominio religioso, la influencia bizantina supo fundir la antigua sociedad rusa, como ya he dicho, en un solo cuerpo, y esto era precisamente la particularidad más notable de la Rusia de entonces.

Las dos tendencias hubieran podido vivir lado a lado sin chocar nunca, ya que sus dominios eran completamente distintos, si la influencia occidental hubiera podido mantenerse dentro de sus límites puramente utilitarios. Pero lo que los moscovitas del siglo XVII no notaron desde el principio, dejando al «occidentalismo» entrąr en su país, eran las ideas que acompañaban cañones y pólvora, mueblaje y relojes, danzas y comedias, trajes y pelucas... Estas ideas englobaban todo el conjunto de la vida material y espiritual de un hombre, pero para poder ser aceptadas y digeridas exigían de este hombre un adelanto cultural, un aprendizaje espiritual; y mientras la corriente bizantina, vuelta "rusista», era un poderoso factor de unión, la corriente "occidentalista" se volvio un factor igualmente poderoso de desunión, ya que, apoderándose de la delgada capa superior de la sociedad rusa, la separó y la arrebató de la masa del pueblo iletrado e ignorante.

$$
\text { ** * }
$$

Pero antes de que esto sucediera, las tendencias «bizantinonacionalista-rusista" $y$ "occidentalista" entraron en un choque abierto, y como la Rusia moscovita era excesivamente unida en lo espiritual, la pelea no se contentó a desencadenar sus furias entre las clases superiores, sino que sacudio al pueblo entero, provocando la primera gran escisión espiritual en el seno de la nación, con que partió en dos su Iglesia.

El principio y la causa inmediata de aquella discordia fué... Ia escuela. Hemos visto ya que los artesanos, oficiales, industriales y los demás extranjeros, que el gobierno de Moscú contrataba en el Occidente, tenían que «enseñar sus artes a los 
rusos sin secreto alguno", pero si ciertos oficios podían ser enseñados sin necesitar preparación cultural alguna, muchas otras novedades occidentales exigían de los discípulos moscovitas un mfnimum de nociones científicas, que les faltaban por completo. De aquí la idea de la conveniencia de cierta preparación cultural, es decir, la necesidad de fomentar ciertas ciencias elementales, independientemente de los fines prácticos, a lo cuales estas hubieran podido ser aplicadas. Esta idea, tan sencilla para nosotros, se abría camino con mucha dificultad en los cerebros rusos del siglo XVII, a pesar de estar protegida y empujada por varios estadistas muy influyentes, que sentían el peligro político del atraso cultural de su país, y esto con una agudeza tanto más grande cuanto que la Moscovia del siglo XVII fué de repente arrastrada en el torbellino de los complicados intereses políticos y económicos de la Europa occidental. Así, ya al zar Miguel (1613-1645), el primer Romanov, Inglaterra y Holanda le ayudaron a arreglar sus pendencias con Polonia y Suecia, en cambio de facilidades que Moscú-vía de tránsito hacia Persia e India-dió a sus negociantes. Pero el rey de Francia, al saberlo, mandó a Moscú una embajada para proponer al zar una alianza en el Oriente contra los ingleses. De otro lado el sultán de Turquía le proponía una alianza contra Polonia, mientras que el rey Gustavo Adolfo de Suecia insistía en una alianza anticatólica. Esta atención inesperada y repentina que las potencias occidentales prestaron a Moscú se explicaba por el hecho de que la guerra de treinta años (1618-1648) ponía a los gobiernos europeos en la obligación de buscar apoyos y sostenes aun fuera del círculo normal de sus relaciones. Así Moscú se vió en la necesidad de cambiar embajadas y organizar todo un cuerpo diplomático, compuesto de lingüistas bastantes cultos, para poder orientarse en el conjunto tan complejo de relaciones diplomáticas de los países europeos, y esta circunstancia fué también un gran estímulo para pensar en la utilidad de la instrucción en general. En fin, la entrada de Rusia en la arena política de la Europa occidental imponía a Moscú las cargas financieras de un gran estado, que su hacienda era incapaz de sostener a causa de la insuficiencia de la producción y el escaso rendimiento del trabajo nacional. No había ni arte ni oficio ni ocupación, empezando por la agricultura, en que los rusos no hubieran debido aprenderlo todo. El comercio se hallaba en las mismas condiciones de inferioridad, y los negociantes rusos, aun teniendo mercancías en sus manos, no les encontraban colocación alguna.

Las crónicas nos han dejado un ejemplo estupendo de la 
impotencia del aparato comercial ruso en los principios del siglo XVII. Leyendo las descripciones de las desgracias que cayeron sobre Rusia durante el período de «interregno», uno se pregunta con perplejidad: ¿cómo ha podido el pueblo ruso sobrevivir a aquellos quince años, du,rante los cuales las ciudades y las aldeas fueron arruinadas y, pör razón de la inseguridad perpetua, nadie se dedicaba al trabajo productivo? A. Palitzin nos dejo en sus notas la explicacion del enigma: dice que la cantidad de trigo que quedaba almacenado en los depósitos de terratenientes, campesinos y comerciantes o que se conservaba en estado de no trillado en almiares y pilas, era tan grande que, «felizmente», el país ha podido vivir quince años sobre aquellas reservas. Ciertamente tres siglos más tarde, los bolcheviques «infelizmente», encontraron reservas de pan sólo para tres años, pero hay que hacer la siguiente reflexión, referente a las reservas del siglo XVII: la agricultura era entonces la ocupación principal del país; supongamos que la previsión de los rusos de entonces fuese tan grande que ellos hubiesen podido almacenar reservas para vivir, ¿cuántos años?, ¡digamos tres, cuatro, cinco! Sería ya una prebenda excesivamente prudente, pero la posibilidad de vivir sobre las reservas de pan quince años seguidos comprueba ante todo la deficiencia del aparato comercial ruso que no encontraba afuera cómo colocar una mercancía de la cual estaba saturado el mercado interior.

Cuando el gobierno de Moscú comprendió todas las razones que imponían el fomento de la instrucción, sus "prikazi"oficinas-ministerios-pensaron en las escuelas. Y aquí hay que comprobar una verdad increíble: hasta la mitad del siglo XVII Rusia no poseía escuela alguna. El arte de leer y escribir, así como las «cifras», las enseñaban clérigos e institutores privados por un precio convenido: para enseñar a leer, tanto; para enseñar a escribir, tanto. No existían manuales ni gramáticas, y los niños aprendían a leer directamente en el salmerio y en el misal, como los aprendices de zapateros aprenden a hacer zapatos. La Iglesia era tan indiferente a las letras, que carecía hasta de una traducción completa de la Biblia y se contentaba con lo que era necesario para el culto. En estas condiciones, ¿dónde podía el gobierno hallar a los profesores y sabios que hubieran podido traducir al ruso los libros indispensables para la primera enseñanza, que hubieron podido completar la versión rusa de las Santas Escrituras? Aun para esto había que dirigirse al Occidente, pero al Occidente cercano, ruso. Y aquí tengo que apartarme por un momento de mi tema principal, para explicar lo que era aquel Occiden- 
te ruso, lo que eran los profesores que Moscú hizo llegar de allí.

En mi exposición he dejado a Kiev en el año 1240, después. de la devastación del gran ducado por los tártaros. Ya he dicho que los restos de su población huyeron en la dirección noreste donde se formó finalmente el estado moscovita; pero los rusos de Kiev se dispersaron también en la dirección del occidente y del norte, incorporándose a los ducados rusos que quedaron intactos por este lado y que entraron en la composición del gran ducado de Lituania, el cual, agrandando su territorio, lleg6 a mediados del siglo XV al mismo resultado en el sudoeste ruso, al cual Moscú llegó en el noreste. Desde luego, esto únicamente en el sentido de engrandecimiento territorial, ya que políticamente, en el sentido nacional, los resultados fueron completamente contrarios a los logrados por Moscú. Ya en 1386, el gran duque de Lituania Jagelo se convirtió al catolicismo y, casándose con la reina de Polonia Iadviga, estableció la unión dual de los dos estados. Cuando en el siglo XV se formó alrededor de Moscú el núcleo nacional ruso, el gobierno de Polonia, mal inspirado, para hacer más estrecha su unión con Lituania, empezó en ésta una activa propaganda católica. El resultado fué absolutamente contrario a las esperanzas: las provincias orientales de Lituania, que eran ortodoxas, se separaron entonces del reino dual y se incorporaron al gran ducado de Moscú. Esto fué la ruina de Lituania, que ya antes, en el momento de firmar su «unión» con Polonia, pidió sus provincias del sur, junto con Kiev, que fueron incorporadas al reino polaco. La población de estas últimas-rusos ortodoxos, gobernados por polacos católicos-, extendiéndose del lado de la estepa, formó la Ukrania ( extremo»), que en el siglo XVII se sublevó contra Polonia y, bajo el nombre de Pequeña Rusia, se juntó, en 1654 , con la Rusia moscovita.

Claro que los ortodoxos del sudeste, mientras duraba la dominación polaca, se hallaban frente al catolicismo en una situación muy diferente a la de sus correligionarios de Moscú. Para defender su fe tenían que enfrentarse con propagandistas católicos especialmente preparados en el colegio romano de San Anastasio, en que la «Congregación romana de propaganda fide» educaba a los misioneros especiales para la conversión de los "cismáticos» del Oriente. Los clérigos ortodoxos, que tenían que luchar contra una propaganda tan sabia, se vieron obligados a usar las mismas armas, es decir, aprender el latín e instruirse, para poder encontrar razones también teológicas en las discusiones dogmáticas. Con este fin, en Kiev fué creada una Academia teológica, que preparaba clérigos sabios. Y 
cuando Moscú sintió por primera vez la necesidad de buscar la luz de la ciencia, era natural que su primer pensamiento se dirigiera hacia $\mathrm{Kiev}$, donde fueron contratados monjes-sabios para la organización de la enseñanza escolar y una nueva edición completa de los libros de culto ortodoxo. Con el mismo fin fueron contratados algunos monjes de Bizancio.

A pesar de que la fe ortodoxa de los recién llegados parecía ser una garantía contra la "nocividad diabólica" de las ciencias occidentales que traían, apenas los nuevos profesores llegaron a Moscú la opinión pública se asustó, temiendo comprometer por las novedades «latinistas» la salvación de su alma. Es que la antigua sociedad rusa no podía apreciar la ciencia y las artes de otro modo, sino como un medio más para aprender la verdad de Dios y salvar su alma. Los recién llegados vieron muy pronto hasta dónde podían llegar las aprensiones fanáticas que ellos despertaban. Así el monje-griego Aseni, que fué contratado como director de la escuela latino-griega, abierta en el monasterio de Chudov, en 1649, poco tiempo después fué desterrado al monasterio de Solovetzki. Pero semejantes episodios no impedían en absoluto el proseguimiento de los planes primitivos. A los monjes de Kiev les fué ordenada la traducción de la Biblia del griego al ruso, así como la traducción y composición de una serie de libros de enseñanza, gramática, diccionarios, geografía y cosmografía y, aun, de algunos libros de alquimia, que interesaban sumamente al gobierno, por si hubiera sido posible fabricar oro con metales comunes.

Estas modestísimas actividades de los monjes ilustrados, que en su conjunto, quizá, no pasaban de unos cincuenta letrados, fueron desde luego causa de la disidencia de los «viejos creyentes». Para entender aquel fenómeno, que hasta hoy día no está completamente liquidado, hay que darse cuenta de la suficiencia religiosa que el pueblo ruso profesaba en aquellos tiempos, consecuencia directa de las condiciones especiales en que se encontraba su Iglesia.

Desde el siglo XI los rusos empezaron a sustituir a los griegos en todos los grados de la escala eclesiástica $\mathrm{y}$, en el siglo XV, hasta el Metropolitano de "Todas las Rusias» se elegía entre los prelados rusos. Ya he dicho que a causa del aislamiento en que se encontró Rusia durante los siglos XIII, XIV y primera mitad del XV, la Iglesia era un símbolo, una bandera, alrededor de la cual se reunía la Rusia entera contra sus enemigos, los agarenos. En estas condiciones todo lo que se refería a la religión, aun a las formas exteriores del culto, adquiría una importancia capital. Mientras tanto la dependencia cano- 
nica de la Iglesia rusa de los patriarcas orientales se mantenía en vigor, y los rusos profesaban el más sincero respeto para su supremo jefe religioso. Pero en el año 1439 la «unión» de Florencia asestó un golpe tremendo al prestigio religioso de los griegos, y cuando, catorce años después, en 1453, los turcos tomaron Constantinopla, los rusos vieron en la desgracia de sus correligionarios una prueba de la ira de Dios, que castigaba a los griegos por haber traicionado el ortodoxismo... Con la toma de Constantinopla todas las Iglesias orientales cayeron bajo el yugo agareno, mientras que Rusia, casi al mismo tiempo, se libertó de aquel yugo definitivamente. Era otra "indicación» del cielo. En fin, cuando en 1589, el patriarca de Constantinopla, Ieremia, estando en Moscú, elevó al metropolitano Job de "Todas las Rusias» a la dignidad de patriarca, la Iglesia rusa logró su independencia definitiva. De aquí no había más que un paso hasta la concepción de la Iglesia rusa como de la Iglesia universal, el único refugio de la verdadera fe cristiana.

A este crecimiento metódico del prestigio de la Iglesia a los ojos de sus fieles hay que añadir la estrecha participación de los fieles en la vida de su Iglesia; para los ortodoxos la Iglesia no es una autoridad exterior, que pueda vivir, actuar y decretar fuera de la reunión de los fieles, sino que es la vida íntima del Espíritu Santo en las almas de todos los fieles que componen su cuerpo. $\mathrm{Y}$ aquí tengo que insistir nuevamente en la importancia que en el sentido de la intimidad religiosa tiene el uso del idioma nacional en los oficios divinos. Cuando estos se celebran en latín, hay muchas probabilidadés de que la introducción de alguna novedad en el texto de oraciones pase inadvertida para la inmensa mayoría de los fieles que no lo entienden. Pero en la Iglesia rusa esto no puede suceder, ya que aun los iletrados siguen el oficio divino palabra por palabra, y la ausencia de una invocación, a la cual está acostumbrado el oído, - la introducción de una nueva plegaria, llamará en seguida la atención de todos los presentes. Con esto la reacción de los fieles a las palabras del sacerdote resulta mucho más intensa. Tomemos un ejemplo. En ciertas ocasiones en la Iglesia ortodoxa se oye la invocación: Kyrie eleison, lo que en griego quiere decir: ¡Señor, ten piedad! La Iglesia católica también conservó esta invocación griega y, supongo, por el mismo motivo que la Iglesia ortodoxa: recuerdo que el culto cristiano ha salido de la Iglesia oriental, griega, de Antioquía, esta «prima primi apostoli sedes», como la llamaba el papa Inocencio I (402-417), en su carta dirigida a Alejandro, obispo de Antioquía, ciudad 
en que por primera vez los cristianos empezaron a llamarse cristianos. Pero lo que quiero expresar es esto: cuando un ortodoxo oye en su Iglesia aquella invocación Kyrie eleison, ¿cuál es la impresión que siente? Creo que ninguna. Los que no saben el significado de aquellas dos palabras no pueden reaccionar de modo alguno; los que las entienden saben que se trata de un homenaje a la madre Iglesia; pero cuando el sacerdote repite la misma invocación en rúso, diciendo: «Señor, ten piedad», la reacción de los fieles resulta instantánea, independientemente del grado de cultura de cada uno. Esta es la razón que cré́ la intimidad entre los rusos y su Iglesia, la razón por la cual las formas exteriores del culto tuvieron para el pueblo moscovita un significado de primera importancia.

$\mathrm{Y}$ sobre aquella gente, tan íntimamente familiarizada con las prácticas religiosas y que ya se sentía molesta por las dudas que les inspiraban las nuevas ciencias respecto a la seguridad religiosa, cayó de repente como un rayo el úkase del patriarca Nicón (1654), que mandaba quemar los viejos libros del culto y sustituirlos por nuevos, que acompañaban cada ejemplar del úkase... ¿Y qué vieron los ojos espantados de los fieles en aquellos libros nuevos? Cosas que, para nosotros, hubieran parecido insignificantes; se corregían errores acumulados por los copistas durante siglos; así, por ejemplo: los rusos se santiguan con dos dedos, y ahora se les explicaba que tenían que santiguarse juntando los tres primeros dedos; el nombre de Jesús, que se escribía en ruso Isús, ahora tenían que escribirlo Iisús; la liturgia la celebraban con siete panes benditos, mientras que ahora bastaban cinco; la invocación jaleluya!, que los rusos repetían dos veces, debía decirse sólo_ una vez, etc. Las innovaciones más radicales se referían al canto, que de unísono se hacía polífono; a los iconos, que los pintores rusos empezaron a imitar sobre las obras de los artistas italianos del renacimiento, y que debían volver a las líneas sobrias y primitivas de la escuela de Bizancio; en fin, se inauguraban los sermones, lo que no correspondía en absoluto a las costumbres de la Iglesia rusa...

¡Qué cosas más insignificantes, dirá el lector, y que no tocan en absoluto las bases de la religión! Desde luego, el apego del pueblo a la letra de su religión, el carácter violento de Nicón, que empezó a quemar los libros antiguos y los iconos nuevos; el hecho de que los errores de los viejos libros fueran corregidos por los monjes-griegos y rusos-occidentalistas, los «latinistas»; la voz de que toda la ciencia "griega y latina" tiene sus raíces en el paganismo, hicieron que el pueblo sospechara del patriarca 
y de sus ayudantes, como nuevos colaboradores del Papa. El pueblo, por lo menos una gran parte del pueblo, quedo entonces horrorizado, y maldijo los nuevos libros. El patriarca Nicón, hombre de grandes méritos, que era hijo de campesino y supo llegar hasta el trono de patriarca, tenía un carácter violento y arbitrario, $y$, en vez de buscar los medios de reconciliarse con su rebaño, culpable sólo de ignorancia y de apego a las tradiciones seculares de su propia Iglesia, reunió un concilio universal, que presenciaban dos patriarcas orientales, y este anatematizó a los insumisos.

Para entender todo el error de aquella escisión, basta decir que el concilio anatematizó a «los viejos creyentes» no por herejía o cisma, ya que no había ni una ni otro, sino por la no obediencia a la autoridad suprema de su Iglesia. Los excomulgados, por su parte, dejaron de reconocer la jerarquíe ortodoxa. Así se realizó aquella disidencia, que dejó en el cuerpo del pueblo heridas todavía no sanadas.

La polémica apasionada entre los dos campos provocó la aparición de panfletos, folletos y aún tratados voluminosos, dirigidos contra la ciencia occidental y que pueden resumirse en las palabras enérgicas de un panfletista que dijo: "El que estudia la geometría es un infame delante de Dios; hay que atenerse a la ciencia ya conocida, dada por Nuestro Señor.)

Siendo la ignorancia el factor principal que permitió y facilitó la incomprensión del verdadero significado que podía tener la actividad del patriarca Nicón, hubiera sido lógico suponer que la hendidura, la escisión que sufrió la Iglesia, era horizontal, es decir, que los que se han desatado pertenecían a las clases bajas de la sociedad, las menos cultas y, por consiguiente, menos aptas a la reflexión serena y cuerda. Sin embargo no fué así: la antigua sociedad moscovita era tan unida, que la hendidura no podía producirse en el sentido horizontal, sin tocar las clases altas; en realidad ella se produjo en sentido vertical: empezando por los miembros de la propia familia del zar, todas las clases y profesiones estuvieron representadas entre los eviejos creyentes", los cuales, lejos de limitar su protesta a los asuntos estrechamente religiosos, se alzaron contra cualesquiera novedades y ciencias que venían del Occidente, englobando en el mismo odio «antiguo-rusista todo el conjunto de ideas y gustos nuevos, que a su parecer no eran más que ediabólicas intrigas latinistas》.

Desde luego la escisión de la Iglesia rusa, en vez de debilitar la corriente *occidentalista», por el espectáculo de las desgracias que esta provocó o por el efecto de los ataques apasionados de 
los "rusistas", dí en realidad un poderoso empuje al fomento de las ciencias occidentales. La razón es fácil de adivinar. Antes de que se realizara la escisión de los viejos creyentes, muchos eran los rusos que creían en la fuerza positiva, bien que conservadora, de las antiguas tradiciones; pero la inexplicable porfía de los opositores de Nicón, que despreciaban la autoridad de su supremo jefe religioso, y, no hacían caso ni de las decisiones del concilio universal de su Iglesia, derrumbó el prestigio de lo antiguo; los hombres que antes miraban con perplejidad lo que quedaba tras sus espaldas, ahora comprendieron que las antiguas tradiciones carecían de una fuerza creadora que les hacía mucha falta, y que la salvación de la patria era posible sólo en la vía del progreso occidental, y, entendiéndolo así, aceptaron con ánimo y confianza las enseñanzas que les ofrecía el Occidente.

De esta manera, antes de que el genio reformador de Rusia, Pedro el Grande, saliera de su cuna, la Rusia moscovita ya se encontraba partida en dos campos hostiles: "rusista» y «occidentalista», cuyas intenciones y medios de acción eran tan claros, que nadie podía quedarse en medio de los dos: y cualquier espíritu pensante tenía que incorporarse al partido que le parecía mejor, más justo o más seguro. 